\title{
Oncocytic Variant of Papillary Thyroid Carcinoma and Associated Lymphocytic Thyroiditis: A Case Report with Review of Literature
}

\author{
Aradhana Mishra, V Jayalakshmi, Uma Pankaj Chaturvedi, Nitin P Chikhale, Richa D Patel, Susan Cherian
}

\begin{abstract}
The oncocytic variant of papillary thyroid carcinoma represents an uncommon neoplasm whose clinicopathological features and biological behavior have not been adequately defined. We report a case of a 36-year-old female with oncocytic papillary thyroid carcinoma and associated lymphocytic thyroiditis. The cytological and histopathological features of this entity are being discussed along with the differential diagnosis and review of literature.
\end{abstract}

Keywords: Papillary carcinoma, Oncocytic, Lymphocytic thyroiditis, Nuclear pseudoinclusions, Nuclear grooves.

How to cite this article: Mishra A, Jayalakshmi V, Chaturvedi UP, Chikhale NP, Patel RD, Cherian S. Oncocytic Variant of Papillary Thyroid Carcinoma and Associated Lymphocytic Thyroiditis: A Case Report with Review of Literature. Int J Head Neck Surg 2013;4(2):89-91.

\section{Source of support: Nil}

Conflict of interest: None declared

\section{INTRODUCTION}

The oncocytic variant of papillary thyroid carcinoma (PTC) is a rare subtype accounting for 1 to $11 \%$ of all PTCs. ${ }^{1-3}$ The histological and cytological criteria for its diagnosis have not been clearly determined. These tumors should be distinguished from other oncocytic thyroid neoplasms because of its different biological behavior and prognostic implications. ${ }^{1}$

\section{CASE REPORT}

A 37-year-old female was referred to our hospital with a swelling in the neck since 3 months. There was no history of any other major medical illness. On examination, a firm swelling of size $4 \times 3 \mathrm{~cm}$ moving with deglutition was noted. Computed tomographic (CT) scan showed a hypodense lesion in the left lobe of thyroid measuring $2 \times 2.3 \times 2.4 \mathrm{~cm}$ with no extrathyroidal extension.

Fine needle aspiration cytology (FNAC) showed cellular smears composed of clusters of cells with abundant granular cytoplasm characteristic of oncocytes. The nuclei were enlarged, pleomorphic and showed pseudoinclusions (Fig. 1). Based on the nuclear features it was diagnosed as PTC.

A total thyroidectomy and neck dissection was performed. On gross examination, the left lobe of thyroid showed a brownish nodule measuring $2.8 \times 2 \times 2 \mathrm{~cm}$ (Fig. 2). The nodule was firm in consistency and showed areas of hemorrhage corresponding to the FNA site. The right lobe showed no gross abnormality. Microscopic examination of the left lobe showed a tumor with a predominantly papillary growth pattern and focal areas showing tumor cells arranged in follicles. The tumor cells were large, polygonal with abundant pink granular cytoplasm characteristic of oncocytes. Nuclei showed classic features of a papillary carcinoma such as optical clearing, overlapping, grooves and pseudoinclusions (Figs 3A to D). A lymphocytic infiltrate was seen within the tumor. Psammoma bodies were not seen. Lymphovascular invasion was not seen. The right lobe of the thyroid and the nontumoral thyroid parenchyma in the left lobe showed many lymphoid aggregates with prominent germinal centers. Of the 28 regional lymph nodes dissected, three showed tumor metastasis with an appearance similar to the primary tumor. Based on the above findings, the case was diagnosed as an oncocytic variant of PTC and associated lymphocytic thyroiditis.

\section{DISCUSSION}

PTC may exhibit a broad spectrum of morphological appearances with different prognostic implications. The oncocytic variant is uncommon accounting for 1 to $11 \%$ of all papillary thyroid carcinomas. The histopathological criteria for diagnosis and biological behavior of this variant remain poorly defined. ${ }^{1-3}$

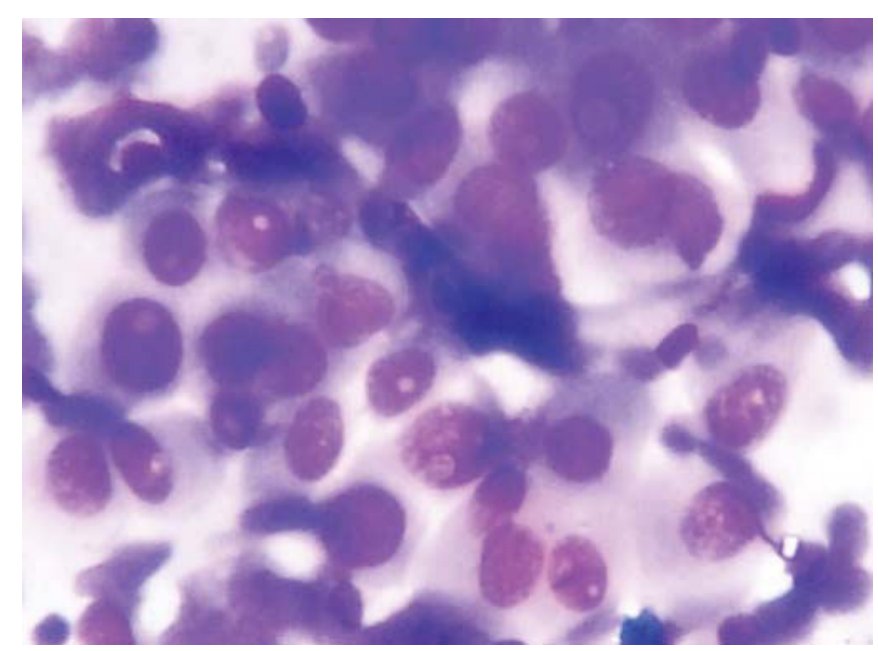

Fig. 1: Giemsa stained cytology smear showing clusters of cells with abundant granular cytoplasm and enlarged pleomorphic nuclei with pseudoinclusions (400x) 
On FNAC, oncocytic variant of PTC is characterized by the presence of oncocytes, which are large cells with abundant granular cytoplasm. These cells are arranged in irregular clusters or papillary aggregates. The nuclear features are those of classic papillary carcinoma namely fine powdery chromatin, grooves and pseudoinclusions. ${ }^{4,5}$

Oncocytic papillary carcinomas are characterized grossly by a distinct mahogany brown appearance and may have a papillary or follicular architecture. Occasional tumors of oncocytic type may appear gray-white. Papillary tumors are characterized by complex branching papillae in which oncocytic cells cover thin fibrovascular stromal cores. ${ }^{1,6-9}$

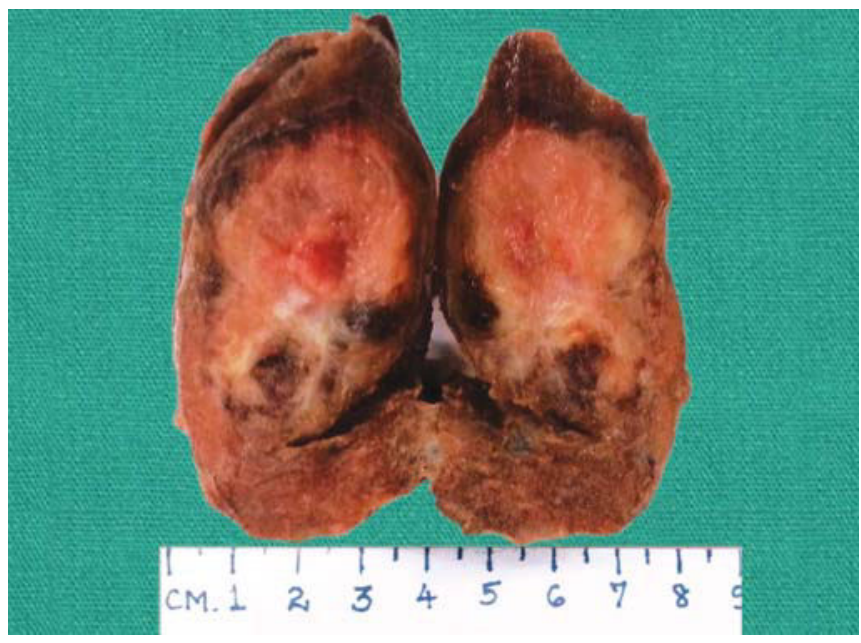

Fig. 2: Gross photograph showing the brownish nodule within the left lobe of the thyroid gland
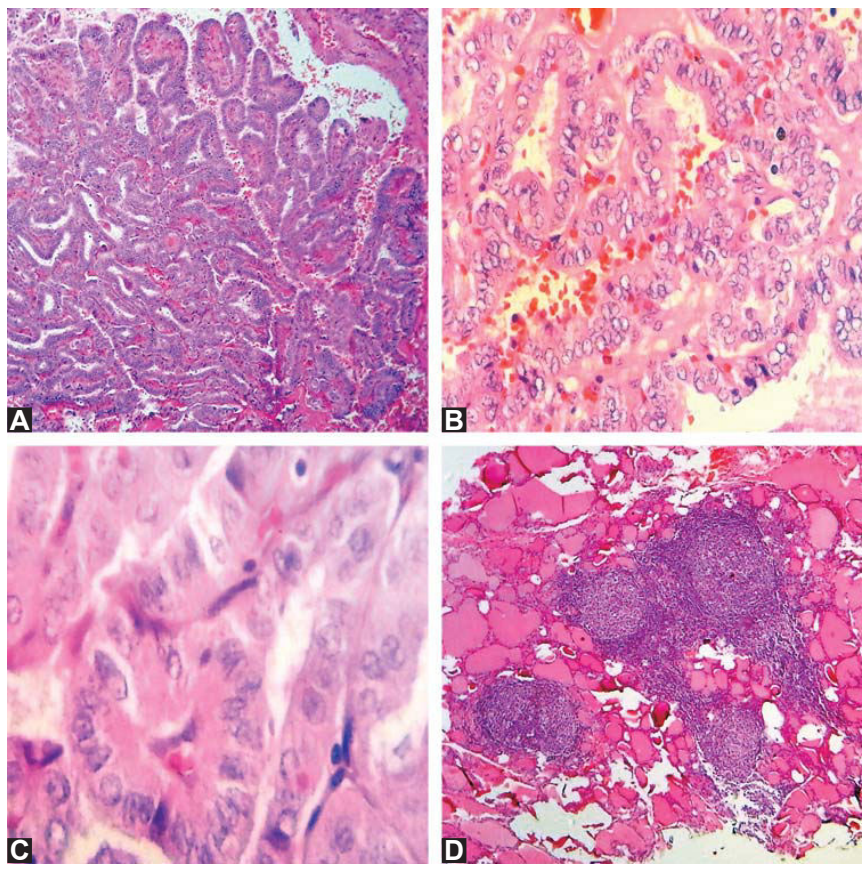

Figs 3A to D: H\&E stained sections showing (A) papillary pattern of growth (40x); (B) optically clear and crowded nuclei (100x); (C) large cells with nuclear grooves and abundant granular eosinophilic cytoplasm (400x), (D) lymphocytic thyroiditis in adjacent thyroid parenchymal $(40 \times)$
Tumors with follicular architecture may be macro- or microfollicular with variable colloid storage. ${ }^{10}$ The tumor may be well delineated or even encapsulated, but careful evaluation usually identifies at least some degree of infiltration of the surrounding capsule. Some lesions are frankly and widely invasive. The diagnosis of the oncocytic variant is based on the nuclear features of these lesions which are identical to those seen in papillary carcinomas of the conventional type. These include nuclear enlargement, oval shape, elongation and overlap, with clearing, resulting in a ground glass appearance, and irregular nuclear contours with nuclear pseudoinclusions and grooves. The oncocytic cells are usually polygonal but may be columnar; they have abundant granular eosinophilic cytoplasm. ${ }^{11}$

In a clinicopathologic study of 15 cases done by Berho et al, ${ }^{13}$ cases showed features of Hashimoto's or lymphocytic thyroiditis in the surrounding uninvolved thyroid parenchyma. The frequent association of these tumors with autoimmune thyroiditis raises the possibility that the oncocytic changes may be pathogenetically related with the latter process. ${ }^{1}$

The biological behavior of the oncocytic variant of PTC seems quite variable, based on different series reported in the literature. It is believed that these discrepancies might reflect the lack of more precise histological criteria to define these neoplasms, leading to inclusion of a broad range of oncocytic tumors within such studies. ${ }^{5}$ Berho et al, found that oncocytic PTC does not appear to behave more aggressively than conventional PTC. ${ }^{1}$

Distinguishing the oncocytic variant of PTC from other oncocytic thyroid neoplasms with different biological behavior is important. The most important entity among these neoplasms is papillary Hurthle cell carcinoma. ${ }^{12,13}$ The nuclear features of papillary Hurthle cell carcinoma include round shape, vesicular chromatin pattern and prominent centrally placed nucleolus. Focal hyperchromasia, binucleation and marked nuclear atypia are frequent accompanying nuclear features of these cells. ${ }^{14}$ Other differential diagnoses include the tall cell variant of PTC and the oncocytic variant of the medullary carcinoma of the thyroid. Neoplastic cells of the tall cell variant of PTC are twice as tall as wide, with elongated dark nuclei. The oncocytic variant of medullary carcinoma is characterized by a solid or follicular growth pattern with prominent oncocytic cell changes, absence of the characteristic nuclear features of PTC, and the presence of more conventional areas of medullary carcinoma within the tumor. ${ }^{15-17}$

\section{CONCLUSION}

The oncocytic variant is a rare and morphologically distinct variant of PTC. However, the histological criteria for its 
diagnosis remain inadequately defined. Hence, additional studies are required to determine its biological behavior and prognostic implications.

\section{REFERENCES}

1. Berho M, Suster S. The oncocytic variant of papillary carcinoma of the thyroid: A clinicopathologic study of 15 cases. Hum Pathol 1997;28(1):47-53.

2. Selzer G, Kahn LB, Alberttyn L. Primary malignant tumors of the thyroid: A clinicopathologic study of 254 cases. Cancer 1977; 40:1501-11.

3. Woolner LB, Beahrs OH, Black BM, McConahey WM, Keating FR Jr. Classification and prognosis of thyroid carcinoma: A study of 885 cases observed in a 30-year period. Am J Surg 1961; 102:354-87.

4. Moreira AL, Waisman J, Cangiarella JF. Aspiration cytology of the oncocytic variant of papillary adenocarcinoma of the thyroid gland. Acta Cytol 2004;48:137-41.

5. Koseoglu RD, Onuk Filiz N. The Oncocytic variant of papillary thyroid carcinoma. Turk J Med Sci 2006;36(6):387-92.

6. Herrera MF, Hay ID, WU PS, Goellner JR, Ryan JJ, Ebersold $\mathrm{JR}$, et al. Hurthle cell (oxyphilic) papillary carcinoma of the thyroid: A variant with more aggressive biologic behavior. World J Surg 1992;16:669-75.

7. Hill JH, Werkhaven JA, Demay RM. Hurthle cell variant of papillary carcinoma of the thyroid gland. Otolaryngol Head Neck Surg 1988;98;338-41.

8. Ludikova M, Ryska A, Korabecna M, Rydlova M, Michal M. Oncocytic papillary carcinoma with lymphoid stroma-Warthin like tumor of the thyroid. A distinct entity with favourable prognosis. Histopathology 2001;39:17-24.

9. Sobrinho-Simoes MA, Nesland JM, Holin R, Sambade MC, Johannesen JV. Hurthle cell and mitochondrion rich papillary carcinoma of the thyroid gland. An ultrastructural and immunohistochemical study. Ultrastruct Pathol 1985;8:131-42.

10. Cheung CC, Ezzat S, Freeman JL, Rosen IB, Asa SL. Immunohistochemical diagnosis of papillary thyroid carcinoma. Mod Pathol 2001;14:338-42.

11. De Lellis RA, Lloyd RV, Heitz PU, Eng C (Eds). World Health Organization Classification of Tumors. Pathology and genetics of tumors of endocrine organs. IARC Press Lyon 2004;61.

12. Barbuto D, Carcangiu ML, Rosai J. Papillary Hurthle cell neoplasms of the thyroid gland: A study of 20 cases (Abstract). Mod Pathol 1990;3:7A.
13. Apel RL, Asa SL, LiVolsi VA. Papillary Hurthle cell carcinoma with lymphocytic stroma: Warthin-like tumor of the thyroid. Am J Surg Pathol 1995;19:810-14.

14. Flint A, Llyod RV. Hurthle-cell neoplasms of the thyroid gland. Pathol Annu 1990;19:37-52.

15. Johnson TL, Lloyd R, Thompson NW, Beierwaltes WH, Sisson JC. Prognostic implications of the tall cell variant of papillary thyroid carcinoma. Am J Surg Pathol 1988;12:22-27.

16. Dominquez-Malagon H, Delgado-Chavez R, Torres-Najera M, Gould E, Albores-Saavedra J. Oxyphilic and squamous variants of medullary carcinoma of the thyroid. Cancer 1989;63:1183-88.

17. Harach HR, Bergholm U. Medullary (C cell) carcinoma of the thyroid with features of follicular oxyphilic cell tumors. Histopathology 1988;13:645-56.

\section{ABOUT THE AUTHORS}

\section{Aradhana Mishra}

Senior Resident, Department of Pathology, Bhabha Atomic Research Centre Hospital, Mumbai, Maharashtra, India

\section{Jayalakshmi}

Postgraduate Resident, Department of Pathology, Bhabha Atomic Research Centre Hospital, Mumbai, Maharashtra, India

\section{Uma Pankaj Chaturvedi (Corresponding Author)}

Consultant, Department of Pathology, Bhabha Atomic Research Centre Hospital, Mumbai, Maharashtra, India, e-mail: umapc@barc.gov.in umapc@rediffmail.com

\section{Nitin P Chikhale}

Senior Resident, Department of Pathology, Bhabha Atomic Research Centre Hospital, Mumbai, Maharashtra, India

\section{Richa D Patel}

Postgraduate Resident, Department of Pathology, Bhabha Atomic Research Centre Hospital, Mumbai, Maharashtra, India

\section{Susan Cherian}

Consultant, Department of Pathology, Bhabha Atomic Research Center Hospital, Mumbai, Maharashtra, India 